\title{
Neural Network Based MPPT Controller for Solar PV Connected Induction Motor
}

\author{
T. Shanthi \\ Assistant Professor (Senior Grade), EEE Department, Kumaraguru College of Technology, \\ Coimbatore, Tamil Nadu, India
}

\begin{tabular}{l}
\hline \hline Article Info \\
\hline Article history: \\
Received Feb 27, 2018 \\
Revised May 1, 2018 \\
Accepted May 17, 2018 \\
\hline Keyword: \\
Incremental conductance \\
Neural network controller \\
MPPT \\
Photovoltaic \\
SEPIC
\end{tabular}

\begin{abstract}
In this paper, Maximum Power Point Tracking Controller is designed based on Neural Network Controller (NNC). This controller will sense the speed of a single phase induction motor which is fed from solar panel. Maximum power point tracking (MPPT) algorithm are required in all photovoltaic (PV) system and in order to increase the efficiency of the system, Incremental Conductance algorithm which is an effective algorithm is used to extract maximum power from the solar panel which supplies an Induction motor of 1HP. To step up the voltage available from the solar panel, the SEPIC DC - DC converter is used. The main advantage of the converter is having non-inverted output. The converter acts as an interface between PV array and motor load. The entire system is modeled and simulated using MATLAB/Simulink software.
\end{abstract}

Copyright $@ 2018$ Institute of Advanced Engineering and Science. All rights reserved.

\section{Corresponding Author:}

T. Shanthi,

Department of Electrical and Electronics Engineering,

Kumaraguru College of Technology,

Chinnavedampatti, Coimbatore-641049, Tamil Nadu, India.

Email: shanthits@gmail.com

\section{INTRODUCTION}

Among all renewable energy sources, solar energy attracts more attention because they provide excellent opportunity to generate electricity. Solar energy is a clean renewable resource with zero emission. Power demand is increasing day by day, so we have to switch to renewable energy sources which are eco-friendly and exist abundant in nature. The maximum power point tracking (MPPT) controller is used to improve the efficiency of the PV system, in which Perturb \& Observe (P\&O) and Incremental Conductance (INC) are frequently used. The incremental conductance algorithm determines the gradient of the P-V curve [1-2]. This method has overcome the disadvantage of the P\&O method to track the peak power under fast varying atmospheric condition. The incremental conductance can determine whether the MPPT has reached the maximum power point (MPP) and stop perturbing the operating point or else the relationship between $\mathrm{dI} / \mathrm{dV} \&-\mathrm{I} / \mathrm{V}$ can be used to determine the direction in which the MPPT operating point must be perturbed [3-6].

A dc to dc converter is needed to boost the voltage from PV panel and commonly available converters are the boost, buck, buck-boost, Cuk, SEPIC [7-8]. In which the single-ended primary inductance converter (SEPIC) is a DC/DC-converter that provides a positively regulated output and non-inverted output. Buck-boost converters are cheaper because they require only a single inductor and a capacitor. But the drawback is the high amount of input current ripple which create harmonics, in many applications, these harmonics require using a large capacitor or an LC filter. This often makes the buck-boost inefficient or expensive, and that can complicate the usage of buck-boost converters is the fact that they invert the output voltage. Cuk converters solve both of these problems by using an extra inductor and capacitor. However, 
both buck-boost and Cuk converter operation cause large amounts of electrical stress on the components, this can result in device overheating or failure. SEPIC converters solve both of these problems.

In this paper, SEPIC converter regulates the dc voltage obtained from the solar panel and feeds the single phase inverter. This single phase inverter runs the single phase Induction motor of 1HP capacity [9-10]. The speed of the induction motor is used as a feedback signal from which voltage is derived and error and change in error are obtained and given to Neural Network controller [11]. The generated pulses from the controller are combined with the pulses obtained from the Incremental Conductance Algorithm of a Solar panel and given to SEPIC converter and desired output voltage is produced.

\section{PROPOSED SYSTEM}

\subsection{Solar panel}

Solar panel uses the light energy photon from the sun to generate electricity through the photovoltaic (PV) effect. The majority of modules use wafer based cells or thin-film cells based on non-magnetic conductive transition metal or silicon. It can provide nearly permanent power at low operating cost and is virtually free pollution. A typical PV cell produces less than 3 watts at approximately $0.5 \mathrm{~V}$ DC. A PV module consists of several PV cells connected in series or parallel. Series connections are responsible for increasing the voltage and the parallel connections are responsible for increasing the current. Figure 1. shows the block diagram of the proposed system.

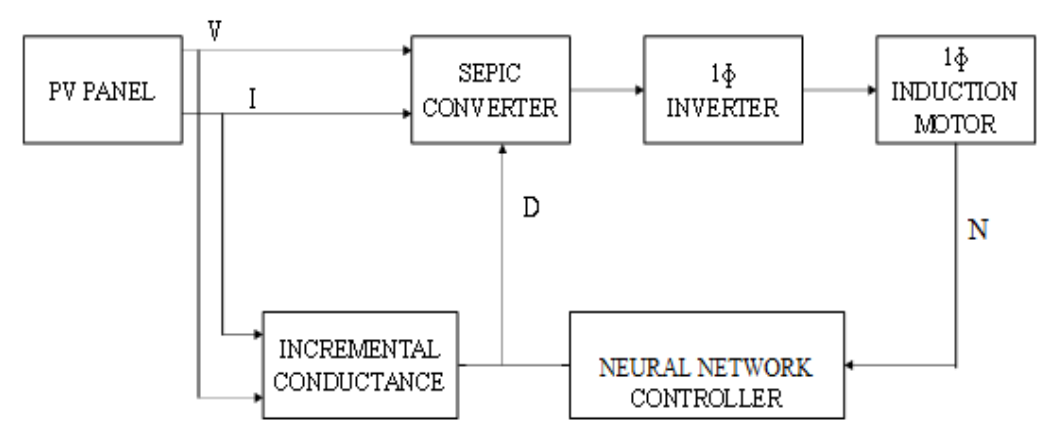

Figure 1. Block diagram of the proposed scheme

\subsubsection{Design of solar panel}

To generate $1 \mathrm{~kW}$ power from the solar panel, four $250 \mathrm{~W}$ panels is connected in series. Due to the series connection, the voltage is increased and the current remains constant. In Table 1 is solar panel.

Table 1. Solar Panel Specification

\begin{tabular}{ccc}
\hline S.No & SPECIFICATION & RANGE \\
\hline 1 & Number of cells & 72 \\
2 & Open circuit voltage $\left(\mathrm{V}_{\mathrm{OC}}\right)$ & $44 \mathrm{~V}$ \\
3 & Short circuit current $\left(\mathrm{I}_{\mathrm{SC}}\right)$ & $7.58 \mathrm{~A}$ \\
4 & Voltage at maximum power $\left(\mathrm{V}_{\mathrm{MP}}\right)$ & $35.55 \mathrm{~V}$ \\
5 & Current at maximum power $\left(\mathrm{I}_{\mathrm{MP}}\right)$ & $7.04 \mathrm{~A}$ \\
\hline
\end{tabular}

\subsection{Maximum power point tracking}

In wind turbines and PV solar systems, to maximum power extraction is possible under all conditions, if MPPT technique is used. PV solar system has many different configurations. A typical solar panel converts only $30-40(\%)$ of the incident solar irradiation into electrical energy. MPPT increases the efficiency of the solar panel rapidly. If they operate at their MPP despite the inevitable changes in the environment, maximum power from the solar panel can be harvested. Over the past decades, many methods to find the MPP have been published and developed. In that most suitable techniques for medium and, large-size photovoltaic applications are P\&O and INC. These techniques have the merits of an easy implementation. 


\subsubsection{Incremental conductance algorithm}

A wide range of MPPT Algorithms are available. Of all the available algorithms, Incremental Conductance Algorithm lends itself well. The incremental Conductance method is often considered, due to its high performances such as easy implementation, high tracking speed, better efficiency and it gets easily adaptable for the changing environmental conditions thus increase the efficiency of PV system. It is found to be the best technique and easily adaptable to the changing environmental conditions. On comparing the efficiency results obtained from Perturb \& Observe (P\&O) 95\% and the Incremental Conductance Algorithm 98\%.

This algorithm senses the output current and voltage of the PV array using sensors. The demerits of $\mathrm{P} \& \mathrm{O}$ method to track the peak power under the fast varying atmospheric condition is overcome by INC method. The incremental conductance can determine the MPPT and if the MPP is reached it stops perturbing the operating point.

$(\mathrm{dP} / \mathrm{dV})_{\mathrm{MPP}}=0$.

$\mathrm{d}(\mathrm{VI}) / \mathrm{dV}=0$.

$\mathrm{I}(\mathrm{dV} / \mathrm{dV})+\mathrm{V}(\mathrm{dI} / \mathrm{dV})=0$

$\mathrm{I}+\mathrm{V}(\mathrm{dI} / \mathrm{dV})_{\mathrm{MPP}}=0$

$(\mathrm{dI} / \mathrm{dV})_{\mathrm{MPP}}=-\mathrm{I} / \mathrm{V}$

The term $-\mathrm{I} / \mathrm{V}$ represents the instantaneous conductance of the PV panel and the term (dI/dV) represents incremental conductance of the PV module. This method is based on the fact that the slope of the power curve is zero at the MPP, if the slope is decreasing, MPP lies on the right side and if the slope is increasing, MPP lies on the left side. This can be given by,

$(\mathrm{dI} / \mathrm{dV})_{\mathrm{MPP}}=-\mathrm{I} / \mathrm{V}$, at the MPP

$(\mathrm{dI} / \mathrm{dV})_{\mathrm{MPP}}>-\mathrm{I} / \mathrm{V}$, on the left

$(\mathrm{dI} / \mathrm{dV})_{\mathrm{MPP}}<-\mathrm{I} / \mathrm{V}$, on the right

The perturbation is repeated until the MPP is reached. Until a change in current is measured, the MPPT continues to operate at the same point. In Figure 2 is flow chart InC algorithm and Basic concept of INC on a P-V curve as shown in Figure 3.

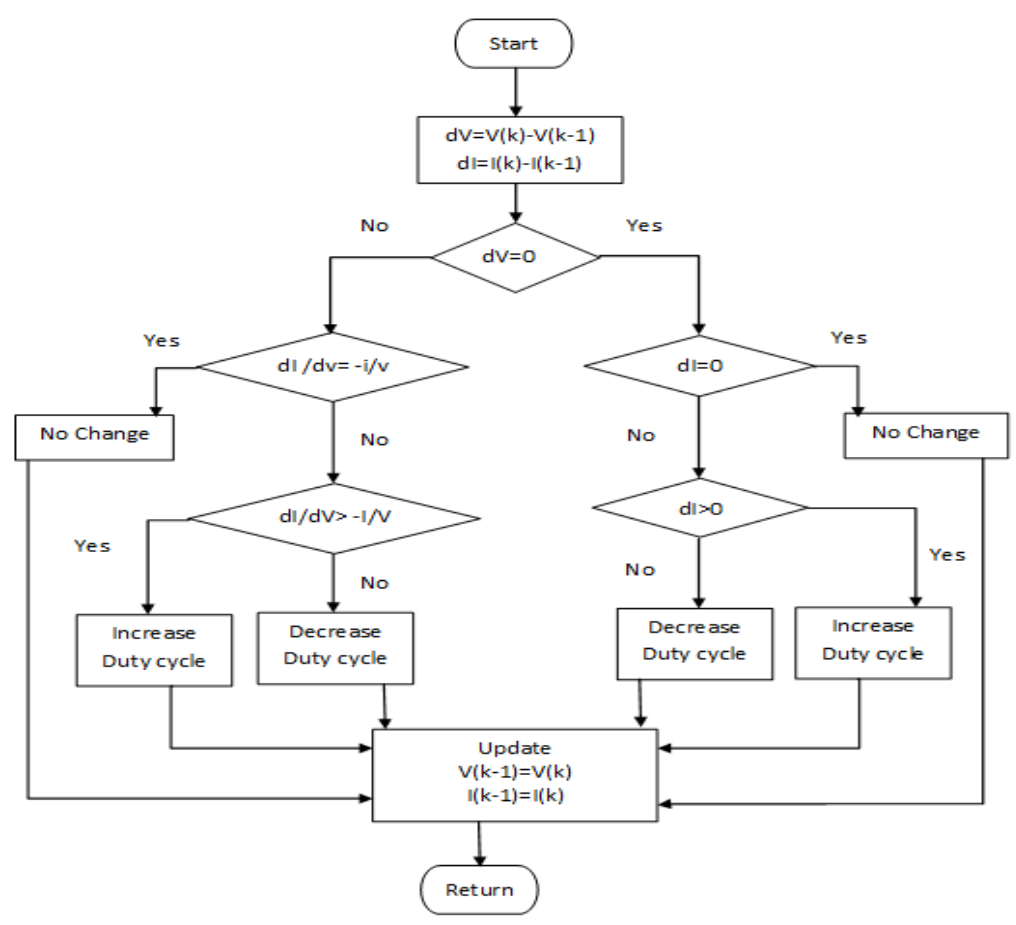

Figure 2. Flow chart for INC algorithm 


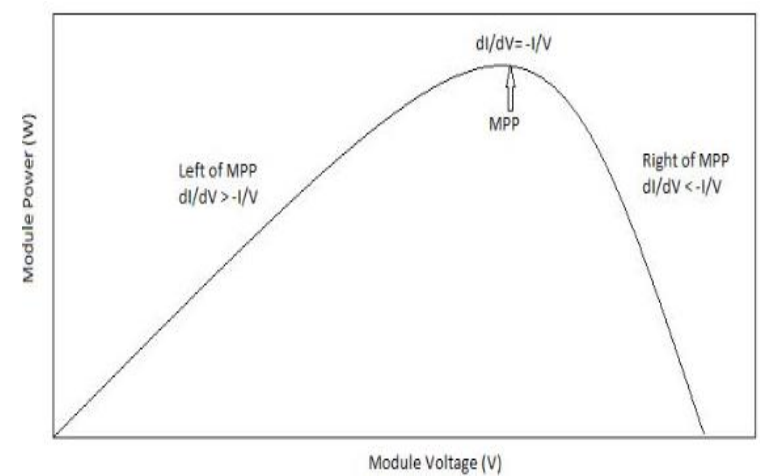

Figure 3. Basic concept of INC on a P-V curve

\subsection{Sepic converter}

The circuit diagram of the SEPIC converter is shown in Figure 4. A SEPIC (single-ended primary inductor converter) is one type of DC-DC converter. It consists of boost converter followed by a buck-boost converter. The main advantage of this converter is capable of providing a non-inverted output (i.e. the output has the same polarity as the input). Its output voltage must be greater than or less than or equal to the input voltage and is widely used in battery operated applications.

The output voltage is controlled by adjusting the duty cycle of the control switch. The control switch is typically a MOSFET, which offers much higher input impedance, low voltage drop and lower switching losses. A SEPIC converter is a fourth order converter, it means these converters have four energy storage elements they are two inductors and two capacitors, and it is used to transfer the energy from input side to output side. The input inductor $\mathrm{L}_{1}$ is together with the MOSFET control switch to be like a boost topology, where the inductor $\mathrm{L}_{2}$ location is similar to a buck-boost topology.

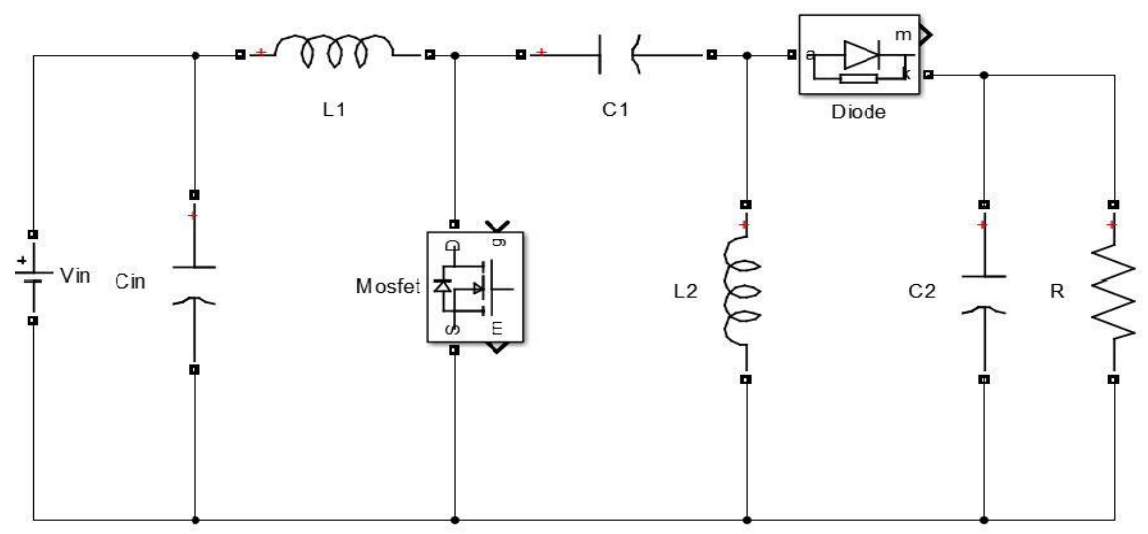

Figure 4. Power circuit of SEPIC converter

\subsubsection{Design calculation}

$$
\begin{array}{ll}
\mathrm{V}_{\text {IN }}=142.2 \mathrm{~V} \\
\mathrm{I}_{\mathrm{IN}}=7.04 \mathrm{~A} \\
\mathrm{f}=15 \mathrm{KHZ} \\
\mathrm{V}_{\text {OUT }}=230 \mathrm{~V} \\
\mathrm{I}_{\text {OUT }}=4 \mathrm{~A} \\
\mathrm{Wh}
\end{array}
$$

Where,

$\mathrm{V}_{\mathrm{IN}}=$ INPUT VOLTAGE

$\mathrm{I}_{\mathrm{IN}}=$ INPUT CURRENT

$\mathrm{f}=$ FREQUENCY

$\mathrm{V}_{\text {OUT }}=$ OUTPUT VOLTAGE 
$\mathrm{V}_{\mathrm{IN}}=$ INPUT VOLTAGE

CALCULATION DUTY CYCLE:

We know that, $\quad \mathrm{D}=\mathrm{T}_{\mathrm{ON}} / \mathrm{T}$

Where,

$\mathrm{T}=\mathrm{T}_{\mathrm{ON}}+\mathrm{T}_{\mathrm{OFF}}$

Similarly,

$\mathrm{D}=\mathrm{V}_{\text {OUT }} / \mathrm{V}_{\text {OUT }}+\mathrm{V}_{\mathrm{IN}}$

$\mathrm{D}=230 / 230+142.2$

$\mathrm{D}=0.6179$

INDUCTOR CALCULATION:

For Inductor $\mathrm{L}_{1}$,

$\mathrm{L}_{1}=\mathrm{V}_{\mathrm{IN}} * \mathrm{D} / 2 * \mathrm{I}_{\mathrm{IN}} * \mathrm{f}$

$\mathrm{L}_{1}=142.2 * 0.6179 / 2 * 7.04 * 15 * \mathrm{e}^{\wedge} 3$

$\mathrm{L}_{1}=0.416 \mathrm{e}-3 \mathrm{H}$

For Inductor L2,

$\mathrm{L}_{2}=\mathrm{V}_{\text {OUT }} *(1-\mathrm{D}) / 2 * \mathrm{I}_{\text {OUT }} * \mathrm{f}$

$\mathrm{L}_{2}=230 *(1-0.6179) / 2 * 4.5 * 15 * \mathrm{e}^{\wedge} 3$

$\mathrm{L}_{2}=0.6457 \mathrm{e}-3 \mathrm{H}$

CAPACITOR CALCULATION:

For Capacitor $\mathrm{C}_{1}$,

$\mathrm{C}_{1}=\mathrm{I}_{\text {OUT }} / \mathrm{V} \triangle$

Where,

$\triangle \mathrm{V}=\mathrm{V}_{\text {OUT }}-\mathrm{V}_{\mathrm{IN}}$

$\mathrm{C}_{1}=3.447 \mathrm{e}-6 \mathrm{~F}$

For Capacitor C2,

$\mathrm{C}_{2}=\mathrm{I}_{\text {OUT }} / \mathrm{V}_{\text {OUT }} * \mathrm{f}$

$\mathrm{C}_{2}=4.54 / 230 * 15 * \mathrm{e}^{\wedge} 3$

$\mathrm{C}_{2}=1.31 \mathrm{e}-6 \mathrm{~F}$

\subsection{Neural networks}

A neural network is a mathematical model inspired by biological neural networks as like in a brain. Human brain learns from experience and stores information's as patterns. In some situation, these patterns are very complicated and allow us the ability to recognize individual faces. So the process of storing information as patterns has a new field in computing. This computing use as massive parallel networks and training of this network done to solve a specific problem [11].

A neural network consists of an interconnected set of artificial neurons, and it process information using a connectionist approach to computation. Integrated circuits are two-dimensional devices with less number of layers for interconnections. In reality, artificial neural networks can be implemented in silicon and basically, all artificial neural networks have a similar structure. In that structure, some neurons interfere to receive input, other neurons interfere with the network output and rest of the neuron has a role but will not be displayed. Basically, the neural network has three layers namely input layer, the output layer and hidden layer. The hidden layer may or may not be present depending on the application used. This neural network for speed control of induction motor has two layers namely input layer and output layer. In Figure 5 is the layout of artificial neural network.

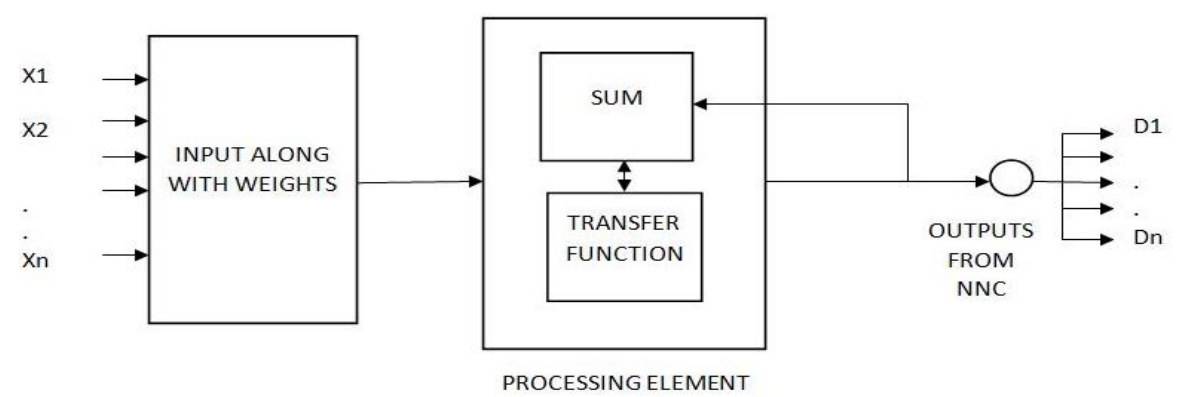

Figure 5. Layout of artificial neural network 


\subsubsection{Training and artificial neural network}

If a network has been framed for a particular application then the next step is training the artificial neural network. To begin this process initial weights are assumed randomly. Training of artificial neural network can be approached in two ways namely supervised and unsupervised. In supervised training, the output is known so input is given as per the desired output. This process involves the comparison of resulting output and desired output so that error value would be generated. The error value so obtained is propagating back and weights are adjusted and above said process continue until desired output is obtained. The set of data which enable this whole process is called "training set". On other unsupervised training will be preceded with random input as desired output is not predictable. So this process is also called as self-organization [12]. In Figure 6 is layout of Typical Neural Network.

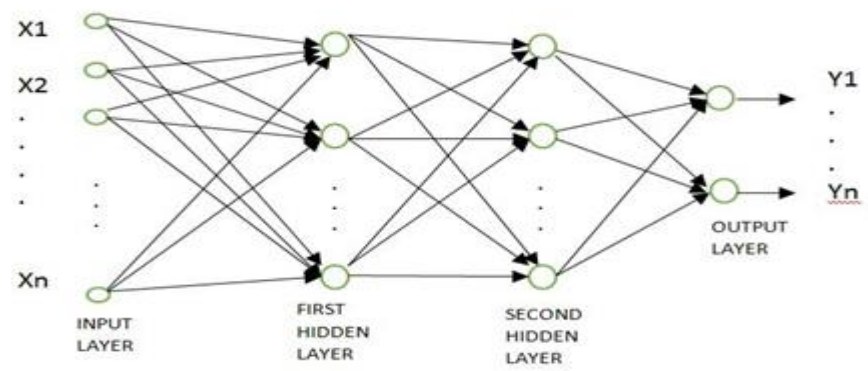

Figure 6. Layout of typical neural network

\subsubsection{Components of artificial neural network}

There are seven major components involved in the artificial neural network. These components are valid whether the neuron is used for input, output or in the hidden layer [13-14].

a. Determination of weight

A neuron receives much input simultaneously. Each input is provided with corresponding weights so that provides an impact on the processing element. Priority to the inputs depends on the weight. So weight can be described as adaptive coefficients which determine the intensity of the input signal and measure the input connection strength. These strengths can be modified during training set. b. Summation function

The first process is to compute the weighted sum of all the inputs mathematically input and weights are in vector form and dot products are carried out between them. Geometrically the dot products represent similarity between inputs and weights. The resultant of the vector products depended upon the direction of vector points. The combination of neural inputs depends upon network architecture sometime activation function is also done and its purpose is to allow the output obtained to vary with respect to time.

c. Transfer function

The obtained weighted sum is transformed to working output through the transfer function. During the process, the weighted sum is compared with a threshold value to determine the network output. If the condition is satisfied, then it generates signal otherwise, it won't produce any signal. The transfer function is generally a non-linear system because linear functions are not useful. Sometimes ramping functions, sigmoid or S-shaped curve are used as transfer functions.

d. Scaling and limiting

The results so obtained are processed through scaling factors and sometimes offset value is added. Limiting is the mechanism which is done when it exceeds the boundary conditions.

e. Output function

Like the biological neuron, there are many inputs and only one output. The output is directly proportional to transfer function result. Competition can occur at one or both of two levels. First, the activity of the artificial neuron is determined and second competition determines the participation of processing element.

f. Error function and back propagated value

In this process difference between current output and desired output is calculated. The change in error is then transformed to error function to match the network architecture. The error value is propagated into the learning function of another processing element; this error term is called as a current error. The current error propagated back and scaled by the learning function multiply by incoming weight to modify the learning cycle. 
g. Learning function:

The purpose of learning is to modify the weight of the inputs in each processing element. The weight is changed to obtain desired output which is called as adaption function.

\subsubsection{Steps involved in framing ANN}

Step1: Input to the Artificial Neural Network

Change in voltage or error voltage from the motor is given as input to the artificial neural network.

Step2: Processing of Input

From multiple inputs, a single input is chosen and assumed minimum value is subtracted and multiplied by the gain which is the ratio of output range to input range and in some situation, additional bias is given to the input. This forms the first layer of an artificial neural network.

Step 3: Output Processing

The output of the layer 1 is fed back as an input to this layer 2 and the output would be a two-dimensional element. This element is made dot products with the weights assumed and then given to the transfer function and the process of step 2 is done in a reverse manner.

\section{SIMULATION MODELING}

\subsection{MPPT modeling using Neural Network Controller (NNC)}

Figure 7 shows the modeling circuit of Neural Network Controller method and its subsystem with incremental conductance algorithm. It shows that the $1 \mathrm{~kW}$ solar panel connected to the SEPIC converter along with single phase induction motor (1HP) as a load. The speed of the single-phase induction motor is used as a feedback signal from which voltage is derived and error and change in error are obtained and given to Neural Network Controller. The generated pulses from the controller are combined with the pulses obtained from the Incremental Conductance Algorithm of a Solar panel and given to SEPIC converter and desired output voltage is produced [15].

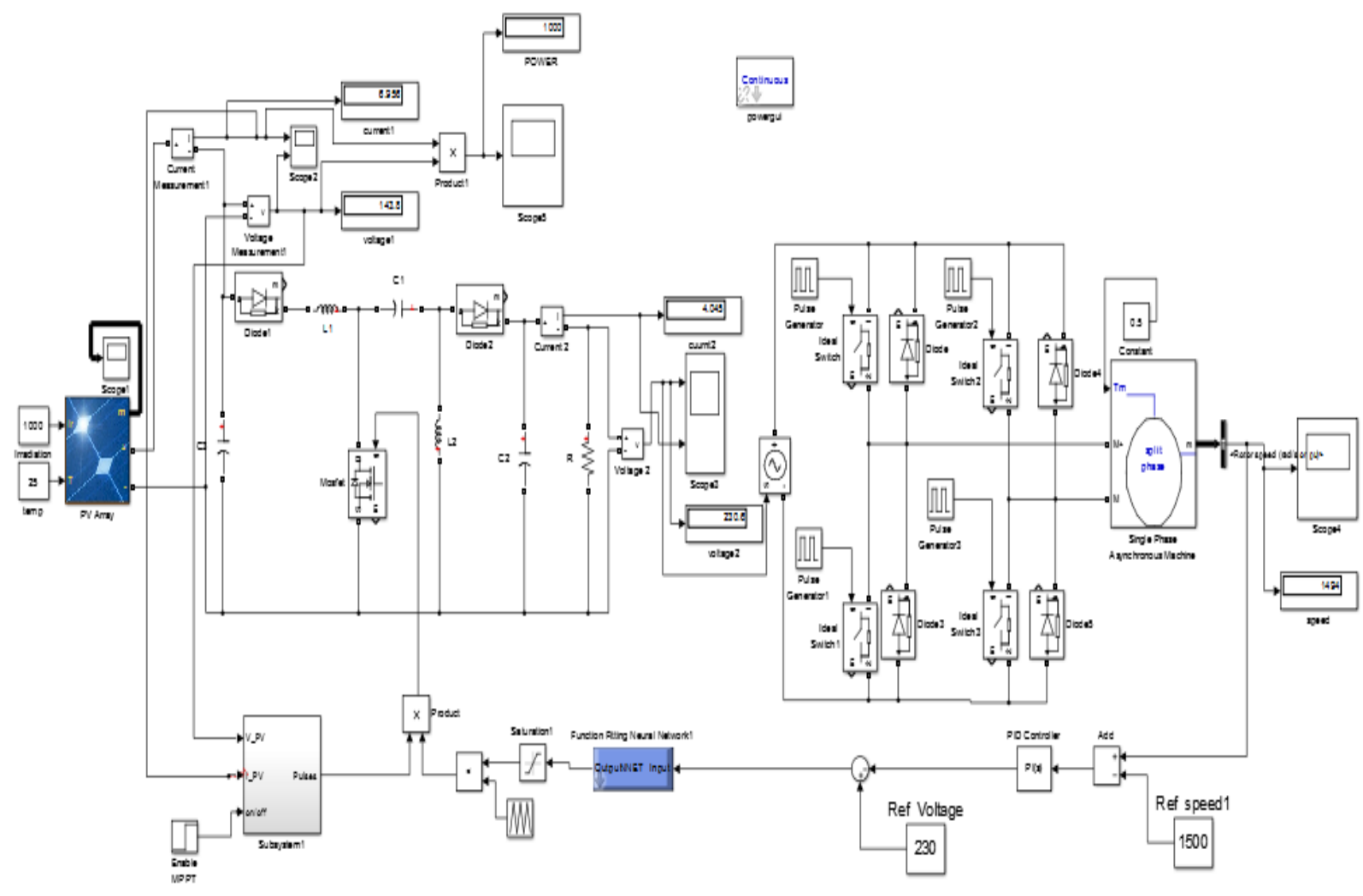

Figure 7. Modeling of circuit for Neural Network Controller (NNC) 


\subsection{Modeling of Neural Network Controller subsystem}

Figure 8 shows the modeling diagram of the neural network subsystem. This compares the output voltage value with given reference value. According to those values of error and change in error, the output voltage is generated from the trained neural networks.

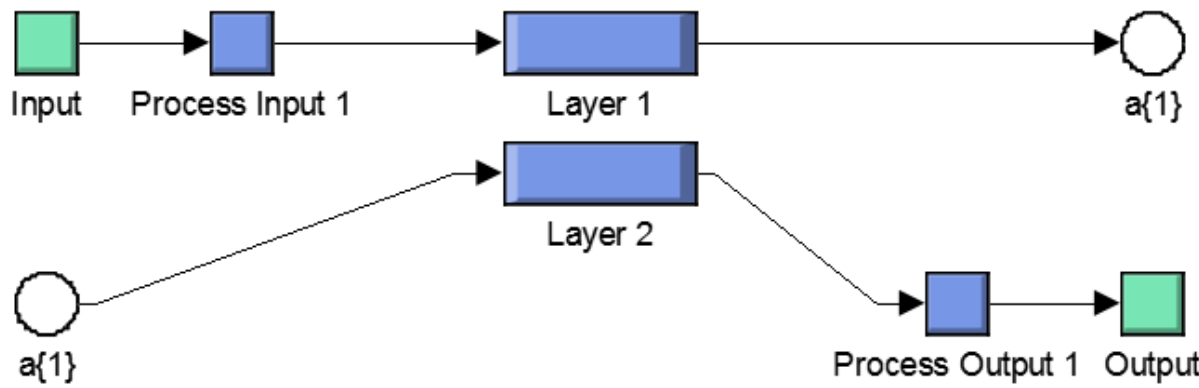

Figure 8. Subsystem circuit for Neural Network Controller

\section{SIMULATION RESULTS AND DISCUSSIONS}

\subsubsection{Parameters of PV model}

The following Figure 9 shows the simulation result of output voltage and output current of the photovoltaic system. The PV panel has been modelled using MATLAB/Simulink and the output voltage and current waveforms have been observed as $143.8 \mathrm{~V}$ and 6.9A respectively. These are depicted in Figure 9. The output power from the PV panel is observed to be $1000 \mathrm{w}$ which has been shown in Figure 10.
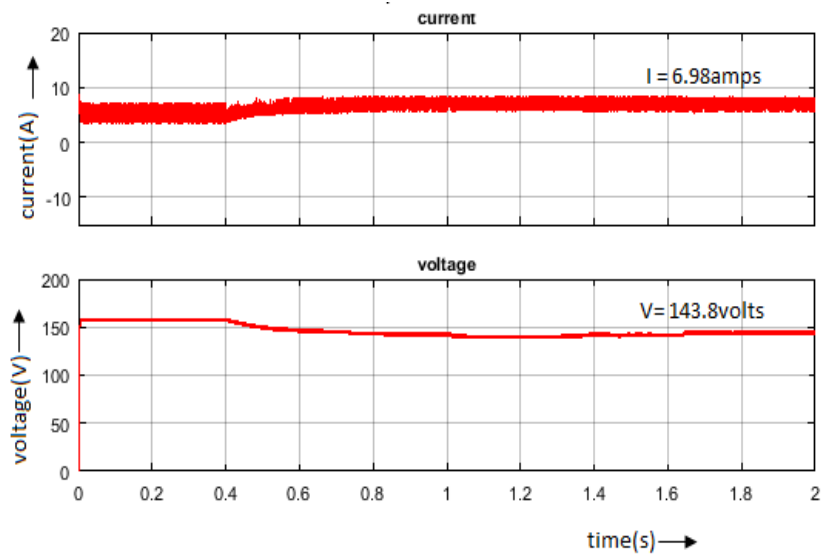

Figure 9. Output voltage \& current of PV with NNC

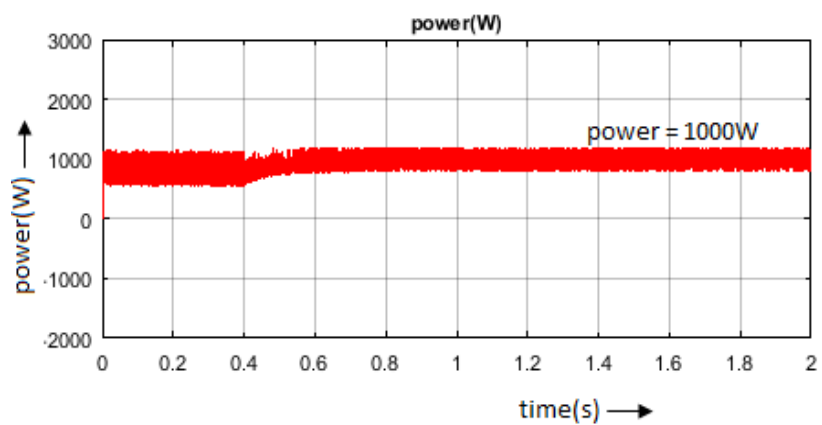

Figure 10. Output power of PV with NNC 


\subsubsection{Output current \& voltage of SEPIC}

The output from the PV panel is fed to the SEPIC converter in order to boost the voltage. The duty cycle of the SEPIC converter is adjusted with the use of neural network controller in order to stabilize the voltage at the output of the converter. The neural network controller is embedded with incremental conductance MPPT algorithm which extracts the maximum power from the PV panel under varying irradiance conditions. The voltage at the output of the SEPIC converter is observed to be $230.6 \mathrm{~V}$ and current is $4.06 \mathrm{~A}$ which has been shown in Figure 11.
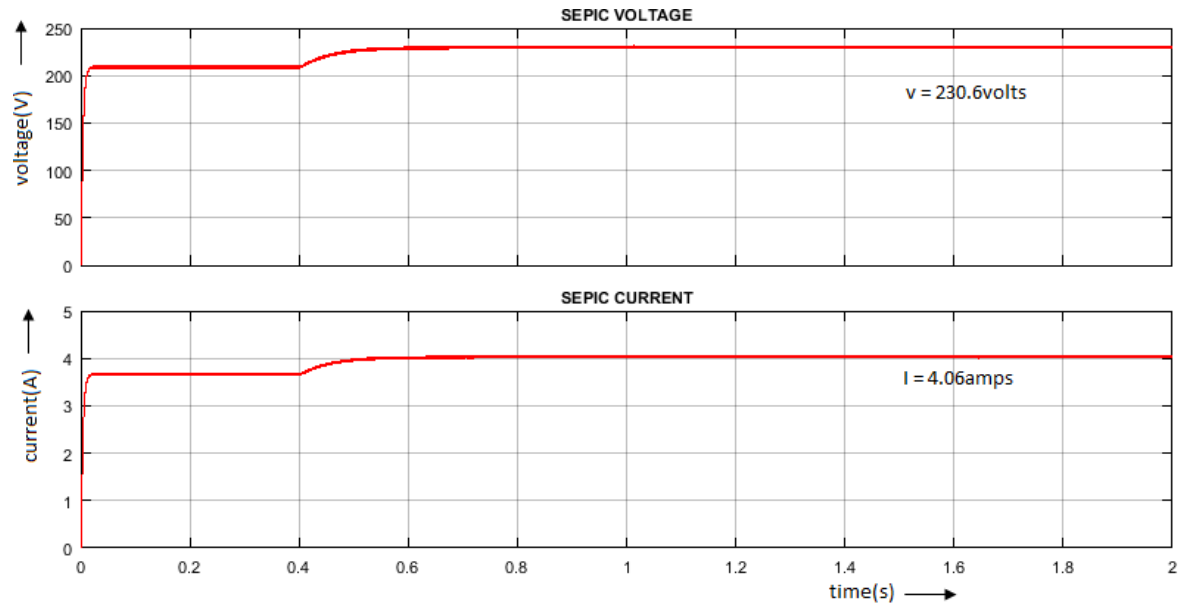

Figure 11. Output voltage \& current of SEPIC converter with NNC

\subsubsection{Speed of the Motor}

The output from the SEPIC converter is fed to the single-phase bridge inverter which converts the voltage to $\mathrm{AC}$ in order to feed it to the single phase induction motor. The output spped of the induction motor is observed. It is found that the speed of the motor gradually increases and attains $1000 \mathrm{rpm}$ and after the instant of $\mathrm{t}=0.5$ seconds, the speed of the motor reaches its steady state value of $1500 \mathrm{rpm}$. Output parameter values are furnished in Table 2, and in Figure 12 is output speed of the motor with NNC.

Table 2. Observed simulation parameters

\begin{tabular}{ccc}
\hline Output voltage & Output current & Speed of the motor \\
\hline $230.6 \mathrm{~V}$ & $4.05 \mathrm{~A}$ & $1500 \mathrm{rpm}$ \\
\hline
\end{tabular}

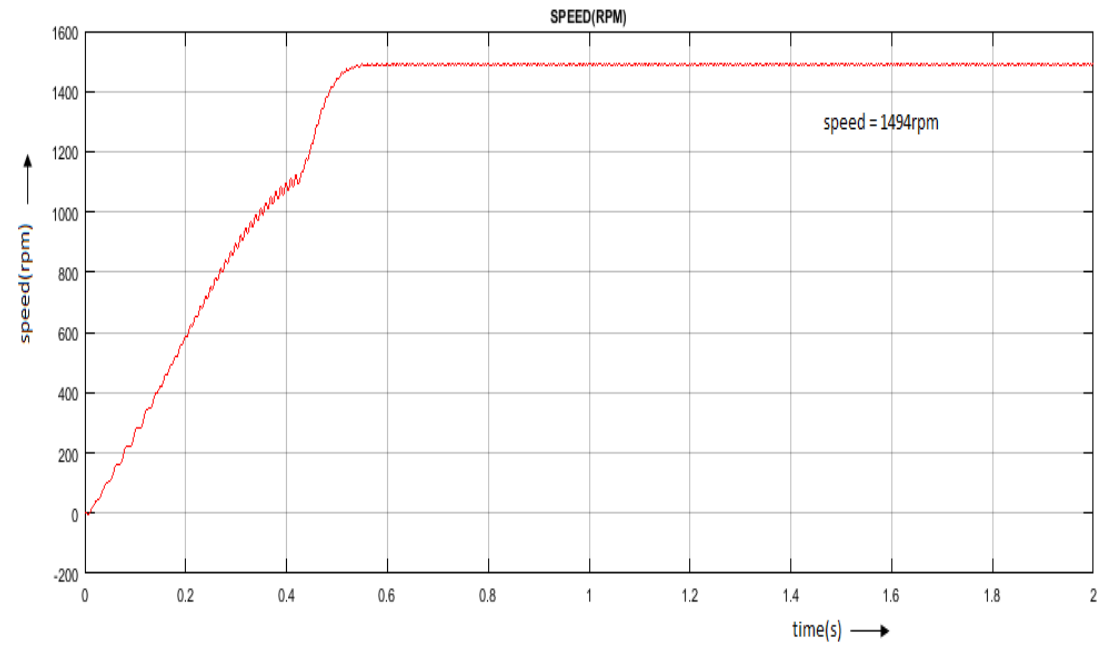

Figure 12. Output speed of the motor with NNC 
Using NNC, the voltage and current from panel is obtained as $143.8 \mathrm{~V}$ and $6.98 \mathrm{~A}$ and output power as $1000 \mathrm{~W}$. The obtained voltage and current is boosted to $230.6 \mathrm{~V}$ and $4.05 \mathrm{~A}$ using SEPIC converter. The inverted voltage is fed to the induction motor at no-load condition which runs at 1500rpm. Comparing with the results of the system with conventional controllers like P,PI and PID controllers, it is observed that the proposed scheme with neural network controller attains the steady state value of speed faster performs better [16]. Table 3 shows the comparison chart of the results from the conventional controller and the neural network controller.

Table 3. Comparison of conventional method and proposed scheme

\begin{tabular}{ccc}
\hline Parameters & Conventional controller & Proposed controller \\
\hline Steady state & $1490 \mathrm{rpm}$ & $1500 \mathrm{rpm}$ \\
speed & 0.75 seconds & 0.5 seconds \\
Settling time & 0.1 & 0.05 seconds \\
Rising time & & \\
\hline
\end{tabular}

\section{CONCLUSION}

This paper highlights the design of the neural network controller for the speed control of single phase induction motor of the rated capacity of 1HP which is driven by solar energy system. The maximum power from the solar panel is extracted using Incremental Conductance Algorithm. The voltage and current obtained from the solar panel is regulated by SEPIC converter which feeds the single phase inverter and that drives the induction motor. The pulses from the respective controller and Incremental Conductance algorithm based MPPT Controller is combined then applied to the SEPIC converter to boost the voltage obtained from solar panel. The speed of the Induction Motor is given as feedback to the controller. The simulation for the neural network controller has been carried out. From simulation results obtained, it is observed that Neural Network controller shows better performance compared to the conventional controller for the speed control of induction motor.

\section{REFERENCES}

[1] Gwo-Bin Wu and Chin-Sien Moo, "Maximum Power Point Tracking with Ripple Current Orientation for Photovoltaic Applications", IEEE Journal of Emerging and Selected Topics in Power Electronics, December 2014, Vol. 2, No. 4.

[2] Gomathi.B, and Sivakami. P, “An Incremental Conductance Algorithm based solar maximum power point tracking system”, International Journal of Electrical Engineering. ISSN 0974-2158 Volume 9, Number 1 (2016), pp. 15-24.

[3] Saravana Selvan, Pratap Nair, Umayal, "A Review on Photo Voltaic MPPT Algorithms, International Journal of Electrical and Computer Engineering (IJECE) ISSN: 2088-8708 Vol. 6, No. 2, April 2016, pp. 567 582.

[4] Mr. ParthaSarathiMaji, Mr. S. Dikshit, Prof. S. Mohapatra, "Modelling and Simulation of Photovoltaic Model Using Incremental Conductance Algorithm" International Journal of Engineering and Management Research, Volume-4, Issue-2, April-2014.

[5] Nur Mohammad, Md. Asiful Islam, Tarequl Karim and Quazi Delwar Hossain, "Improved Solar Photovoltaic Array Model with FLC Based Maximum Power Point Tracking", International Journal of Electrical and Computer Engineering (IJECE) ISSN: 2088-8708 _ 717 Vol. 2, No. 6, December 2012, pp. 717 730

[6] T. Shanthi, and N. AmmasaiGounden, "Power electronic interface for grid-connected PV array using boost converter and line-commutated inverter with MPPT", International Conference on Intelligent and Advance systems, pages: 882-886, DOI: 10.1109/ICIAS.2007.4658513.

[7] James Dunia, Bakari. M and M. Mwinyiwiwa, "Performance Comparison between ĆUK and SEPIC Converters for Maximum Power Point Tracking Using Incremental Conductance Technique in Solar Power Applications", International Journal of Electrical, Computer, Energetic, Electronic and Communication Engineering Vol. 7, No: 12, 2013.

[8] Mohamed Tahar Makhloufi, Yassine Abdessemed, Mohamed Salah Khireddine, "A Feed forward Neural Network MPPT Control Strategy Applied to a Modified Cuk Converter",International Journal of Electrical and Computer Engineering (IJECE) ISSN: 2088-8708 Vol. 6, No. 4, August 2016, pp. 1421 1433.

[9] Sangeetha S, and Jitha joseph "Design and Implementation of Sepic Converter Based PV System Using Modified Incremental Conductance Algorithm", International Conference on Electrical, Electronics, and Optimization Techniques (ICEEOT) - 978-1-4673-9939-5/16/\$31.00 @2016 IEEE.

[10] F. Lftisi, G. H. George, A. Aktaibi, C. B. Butt, and M. A. Rahman, "Artifical neural network based speed controller for induction motors", 978-1-5090-3474-1/16/\$31.00@2016 IEEE.

[11] Whei-Min Lin, Chih-Ming Hong, and Chiung-Hsing Chen, "Neural-Network-Based MPPT Control of a Stand-Alone Hybrid Power Generation System", IEEE Transactions on Power Electronics, Vol. 26, No.12, December-2011. 
[12] Ankit Gupta, Pawan Kumar, Rupendra Kumar Pachauri, Yogesh K. Chauhan, "Performance Analysis of Neural Network and Fuzzy Logic Based MPPT Techniques for Solar PV Systems", 978-1-4799-6042-2/14/\$31.00 @2014 IEEE.

[13] Seong-Hwan Kim, Tae-Sik Park, Ji-Yoon Yoo, and Gwi-Tae Park," Speed-Sensor less Vector Control of an Induction Motor Using Neural Network Speed Estimation”, IEEE Transactions on Industrial Electronics, Vol. 48, No. 3, June 2001.

[14] A. Goedtel, I. N. Silva, P. J. A. Serni, and C. F. Nascimento, "Speed Estimation for Induction Motor using Neural Networks Method”, IEEE Latin American Transaction, Vol. 11, No. 2, Mar 2013.

[15] Pedro Ponce, Arturo Molina and Arturo Tellez, "Neural network and Fuzzy logic in a Speed close loop for DTC Induction motors", 978-1-4799-4683-9/14/\$31.0@2014IEEE.

[16] Hanan Mikhael D., Habbi Hussein Jalil Ajeel, and Inaam Ibrahim Ali, "Speed Control of Induction Motor using PI and V/F Scalar Vector Controllers “, International Journal of Computer Applications Volume 151 No.7, 0975-8887 October 2016.

\section{BIOGRAPHY OF AUTHOR}

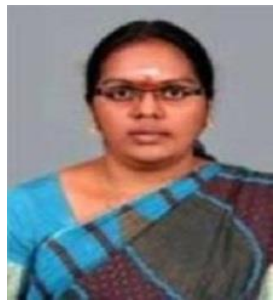

T. Shanthi received her bachelor's degree from Institute of Road and Transport Technology, Erode, Tamilnadu, India in Electrical and Electronics Engineering during 1999. She received her Master's degree from National Institute of Technology, Tiruchirappalli, India during 2007. She is pursuing $\mathrm{PhD}$ at anna university, Chennai in the area of power electronics applications in renewable energy systems She is currently working as Assistant Professor at the department of Electrical and Electronics Engineering in Kumaraguru College of Technology, Coimbatore, India. She has published number of papers in international scopus indexed journals and IEEE conferences. She has number of citations, h-index and i10 index for her publications. Her area of research includes renewable energy systems, hybrid integration, microgrid, electromagnetic fields, power system analysis, soft computing and optimization techniques. 